\title{
FAST LATERAL EPITAXIAL OVERGROWTH OF GALLIUM NITRIDE BY METALORGANIC CHEMICAL VAPOR DEPOSITION USING A TWO-STEP PROCESS
}

\author{
H. Marchand, J.P. Ibbetson, ${ }^{*}$ P.T. Fini, ${ }^{* *}$ X.H. Wu, ${ }^{* *}$ S. Keller, \\ S.P. DenBaars, ${ }^{* *}$ J.S. Speck, ${ }^{* *}$ U.K. Mishra \\ *ECE Dept., University of California, Santa Barbara, CA 93106 \\ **Materials Department, University of California, Santa Barbara, CA 93106
}

Cite this article as: MRS Internet J. Nitride Semicond. Res. 4S1, G4.5 (1999)

\begin{abstract}
We demonstrate a two-step process wherein the lateral epitaxial growth (LEO) of GaN from $<10 \overline{1} 0>$-oriented stripes is initiated at a low V/III ratio to produce smooth, vertical $\{11 \overline{2} 0\}$ sidewalls, and where the V/III ratio is subsequently raised in order to increase the lateral growth rate. We find that the formation of the $\{1 \overline{1} 01\}$ facets is inhibited using this two-step process, and that it is possible to maintain the $\{11 \overline{2} 0\}$ sidewalls while achieving a large lateral growth rate. The ratio of lateral to vertical growth rate has been increased by up to factor of 2.6 using this approach relative to identical growth conditions without the initiation at low V/III ratio. The effect of lateral growth rate on the structural properties of the stripes is discussed.
\end{abstract}

\section{INTRODUCTION}

Lateral epitaxial overgrowth (LEO) is an attractive method to produce GaN films with a low density of extended defects, which is beneficial both to studies of the fundamental properties of the GaInAlN materials system and to GaN-based device technology. Recent studies have confirmed that the density of threading dislocations (TDs) is reduced by 3-4 orders of magnitude in the LEO material grown on $6 \mathrm{H}-\mathrm{SiC}^{1}, \mathrm{Al}_{2} \mathrm{O}_{3}{ }^{2,3,4}$, and $\mathrm{Si}(111)^{5}$ substrates, and the mechanisms of threading dislocations evolution with respect to the facet configuration of the LEO stripes have been investigated. ${ }^{1,4,6,7}$ Optical studies of LEO GaN ${ }^{8,9,10}$ and InGaN quantum wells ${ }^{9}$ have been reported. Finally, the use of LEO GaN has resulted in marked improvements in the lifetime of laser diodes, ${ }^{11}$ while GaN p-n junctions, ${ }^{12}$ InGaN single ${ }^{13}$ and multiple ${ }^{14}$ quantum well light emitting diodes, and GaN/AlGaN heterojunction field-effect transistors ${ }^{15}$ fabricated on LEO $\mathrm{GaN}$ exhibit a $\sim 3$ orders of magnitude reduction of the leakage current compared to identical devices based on bulk GaN.

LEO GaN is obtained by performing a regrowth on a conventional GaN layer (e.g. $\mathrm{GaN} / \mathrm{Al}_{2} \mathrm{O}_{3}$ ) that is partially masked by an amorphous layer such as $\mathrm{SiO}_{2}$ or $\mathrm{Si}_{3} \mathrm{~N}_{4}$. The process is anisotropic and can be characterized by two extreme crystalline orientations when using stripes as mask openings. ${ }^{16}$ Stripes aligned along the $\langle 11 \overline{2} 0\rangle$ orientation are bound by smooth $\{10 \overline{1} 1\}$ facets under a wide range of growth conditions ${ }^{17}$ and tend to exhibit slow lateral overgrowth. ${ }^{16}$ On the other hand, $\left\langle 10 \frac{1}{10}>\right.$-oriented stripes exhibit a wider variety of sidewall facets and lateral growth rates. We have recently reported ${ }^{18}$ that the morphology of such stripes depends on the growth temperature and fill factor, ${ }^{9}$ and proposed that these effects result from variations of the V/III ratio with temperature (due to incomplete decomposition of $\mathrm{NH}_{3}$ ) and pattern geometry (related to differential enhancement of $\mathrm{Ga}$ and $\mathrm{N}$ species supply from the mask regions), in relation to the configuration of the dangling bonds on the various facets. This interpretation appears to be confirmed by a systematic study of the effect of the input V/III ratio. ${ }^{20}$ At low V/III ratio, the sidewalls consist of inclined $\{11 \overline{2} 2\}$ facets and the lateral growth rate is small. As the V/III ratio is increased, smooth vertical $\{11 \overline{2} 0\}$ facets appear; in this regime the lateral growth 
rate varies approximately linearly with the V/III ratio, up to the point where $\{10 \overline{1} 1\}$ facets are formed, which results in a jagged morphology and a drop of the lateral growth rate.

For device applications it is desirable to maximize the lateral growth rate while avoiding the formation of jagged sidewalls. In this paper we report on a two-step process that results in a reduction of the growth time necessary to achieve full coalescence of adjacent LEO stripes. The overgrowth is initiated in conditions that lead to smooth sidewalls, after which the growth parameters are changed to increase the lateral growth rate. We show that the stripe morphology is essentially determined by the growth conditions of the first overgrowth step, which greatly extends the range of conditions to achieve smooth LEO stripes.

\section{EXPERIMENT}

The LEO GaN was grown on $2 \mu$ m-thick GaN prepared by MOCVD on 2-inch diameter sapphire wafers using a conventional two-step process. ${ }^{21}$ Samples were coated with $200-\mathrm{nm}$ thick $\mathrm{SiO}_{2}$ using plasma-enhanced chemical vapor deposition, and $5 \mu \mathrm{m}$-wide openings oriented in the $\langle 10 \overline{1} 0\rangle$ direction ${ }^{16}$ were patterned using standard UV photolithography and wet chemical etching. The mask width was varied to give fill factors ${ }^{19}$ of 0.01 to 0.5 , corresponding to mask widths of 495 to $5 \mu \mathrm{m}$. The LEO growth was performed at 76 Torr and $1060^{\circ} \mathrm{C}$ using hydrogen as the carrier gas. No dopants were intentionally introduced during growth.

In this paper we discuss the properties of six samples whose growth parameters are listed in Table I. Uncoated samples were characterized by scanning electron microscopy (SEM) using a JEOL 6300F field emission microscope operating at $15 \mathrm{kV}$. Specimens for transmission electron microscopy (TEM) were prepared by wedge polishing followed by standard $\mathrm{Ar}^{+}$ion milling. Images were recorded on a JEOL 2000FX microscope operated at $200 \mathrm{kV}$. The roomtemperature photoluminescence was excited using a HeCd laser $\left(325 \mathrm{~nm}, \sim 20 \mathrm{~mW} / \mathrm{cm}^{2}\right)$ and detected using a $1 / 8 \mathrm{~m}$ grating monochromator and a photomultiplier tube.

\section{RESULTS}

Figure 1(a,b) shows SEM micrographs of sample A, overgrown in a single 15-minute step using $3.6 \mathrm{slm}$ of $\mathrm{NH}_{3}$, which results in jagged sidewalls ( $\{10 \overline{1} 1\}$ facets). Figure 1(c,d) shows micrographs of sample $\mathrm{B}$, grown under the same conditions except that the overgrowth was initiated under half the $\mathrm{NH}_{3}$ flow for the first 3 minutes. Sample B shows smooth vertical sidewalls $(\{11 \overline{2} 0\})$ and a slightly larger lateral growth rate. Although the samples shown in Fig. 1 were grown consecutively using the same $\mathrm{GaN} / \mathrm{Al}_{2} \mathrm{O}_{3}$ substrate and patterning run, the elimination of the $\{10 \overline{1} 1\}$ facets following the overgrowth initiation at low V/III ratio is reproducible and appears to be insensitive to process parameters such as threading dislocation density of $\mathrm{GaN} / \mathrm{Al}_{2} \mathrm{O}_{3}$ substrate, fill factor, and growth parameters of the second step.

Table I Precursor flow and step durations

\begin{tabular}{|c|ccc|ccc|}
\hline Sample & $\begin{array}{c}\text { Duration } \\
(\mathrm{s})\end{array}$ & $\begin{array}{c}\text { Step 1 } \\
\text { TMGa } \\
(\mu \mathrm{mol} / \mathrm{min})\end{array}$ & $\begin{array}{c}\mathrm{NH}_{3} \\
(\mathrm{slm})\end{array}$ & $\begin{array}{c}\text { Step 2 } \\
\text { Duration } \\
(\mathrm{s})\end{array}$ & $\begin{array}{c}\text { TMGa } \\
(\mu \mathrm{mol} / \mathrm{min})\end{array}$ & $\begin{array}{c}\mathrm{NH}_{3} \\
(\mathrm{slm})\end{array}$ \\
\hline \hline A & 900 & 100 & 3.6 & --- & --- & --- \\
$\mathrm{A} 2$ & 3600 & 100 & 3.6 & --- & --- & -- \\
\hline B & 90 & 100 & 1.8 & 810 & 100 & 3.6 \\
B2 & 900 & 100 & 1.8 & 900 & 100 & 3.6 \\
\hline C & 90 & 100 & 1.8 & 1710 & 50 & 1.8 \\
\hline D & 90 & 100 & 1.8 & 1710 & 50 & 3.6 \\
\hline
\end{tabular}



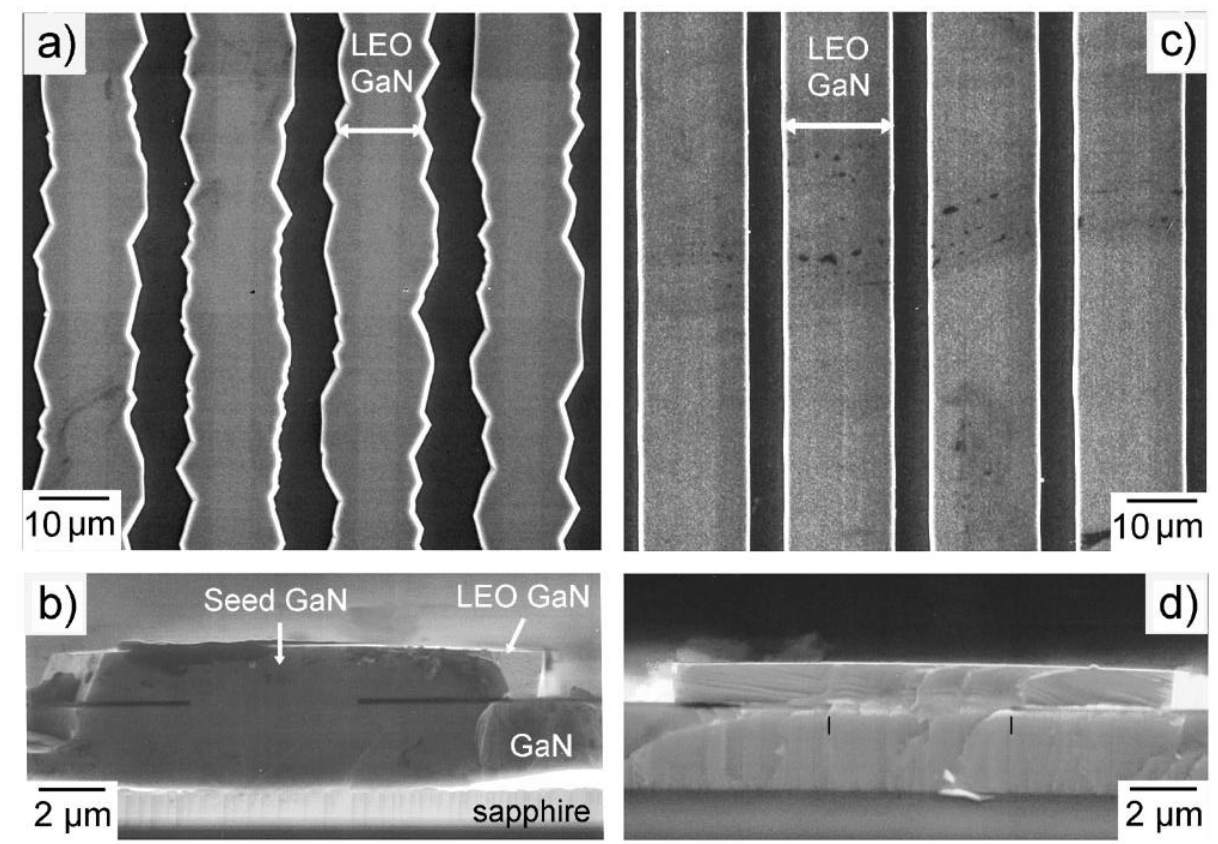

Figure 1 SEM micrographs of sample A (a: plan view, b: crosssection) and Sample B (c: plan view, d: crosssection) for a fill factor of 0.25 . The edges of the mask are indicated by dark markers in (d).

Figure 2 illustrates the effect of TMGa and $\mathrm{NH}_{3}$ flow rates on the ratio $r$ of lateral to vertical growth rate. In Refs 18 and 20 we have shown that an increase in fill factor (i.e. reduction of the mask spacing) has a similar effect as an increase in the input V/III ratio; thus the horizontal axis can be understood both as a geometrical factor and as an indirect V/III scale. The curve for sample A shows that $r$ rolls off as the $\{10 \overline{1} 1\}$ facets appear at high fill factors for the one-step process. On the other hand, $r$ increases monotonically with fill factor for the samples grown in two steps (B, C, and D). Comparing samples A and B at the high-fill factor end of their respective curves provides a conservative estimate of $\sim 30 \%$ for the increase in $r$ associated with

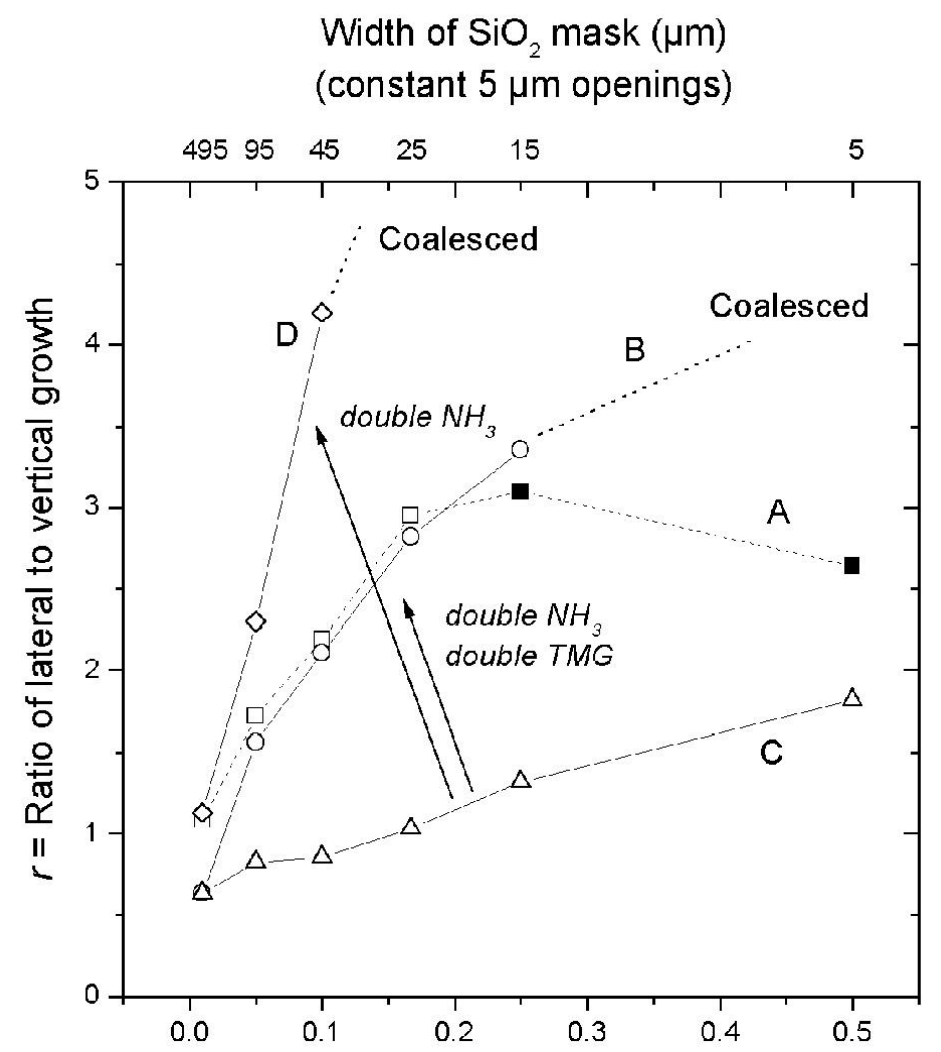

Fill factor
Figure 2 Ratio of lateral to vertical growth as a function of fill factor for samples A-D. The lateral growth is defined as the width of the GaN growth above the mask opening. The data points for a given curve are results from a single growth on a sample patterned with the various fill factors. The solid symbols indicate jagged sidewalls ( $\{10 \overline{1} 1\}$ facets). 
the two-step

process (the actual

gain was limited

by the rapid coalescence of sample B). A typical sample grown in one step in the conditions for sample $\mathrm{D}$ at a fill factor of 0.1 would exhibit jagged sidewalls and $r \approx 1.6$ (not shown); the twostep process (sample D) results in smooth sidewalls and $r=4.2$, a factor of 2.6 larger.

Figure 3

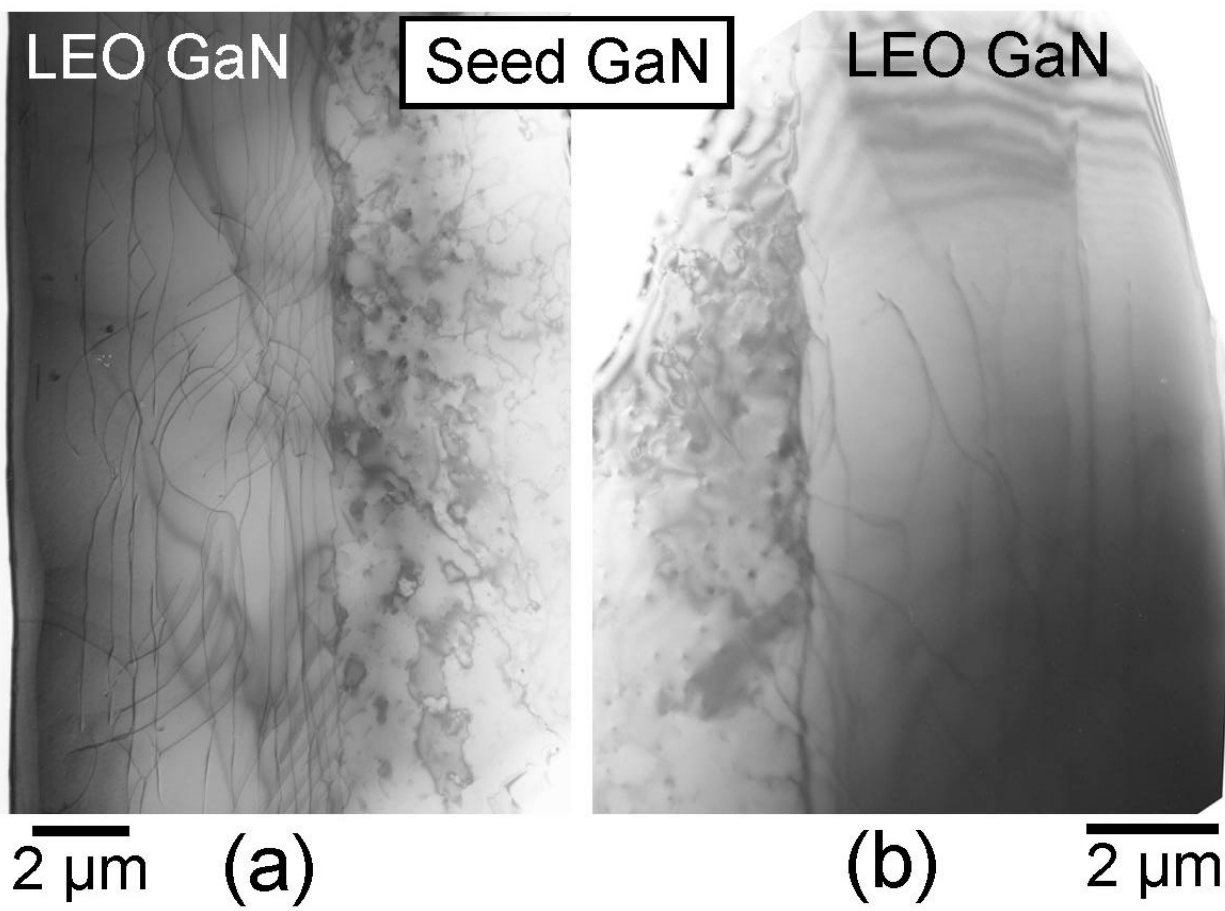

Figure 3 Plan view TEM micrographs of (a) Sample A2 and (b) Sample B2 (bright field, $g=2 \overline{1} 10)$.

shows plan-view TEM micrographs of samples A2 and B2, which are similar to samples A and $\mathrm{B}$ except for the growth duration. For both samples the LEO region is free of threading dislocations. The LEO region of sample A2 (Fig. 3a) contains a large number of dislocations with line direction along the $<10 \overline{1} 0>$ direction (parallel to the stripe direction); a significant fraction of those dislocations bends towards the $\langle 11 \overline{2} 0\rangle$ direction perpendicular to the stripe. Sample B2 (Fig. 3b) also exhibits dislocations with line direction parallel to the stripe direction, however their density is much smaller than for sample A2. Although additional microstructural studies are required to fully understand dislocation evolution during LEO, Fig. 3 clearly indicates that the LEO stripe overgrown in two steps contains much fewer extended defects than the stripes grown with the onestep process. This can be

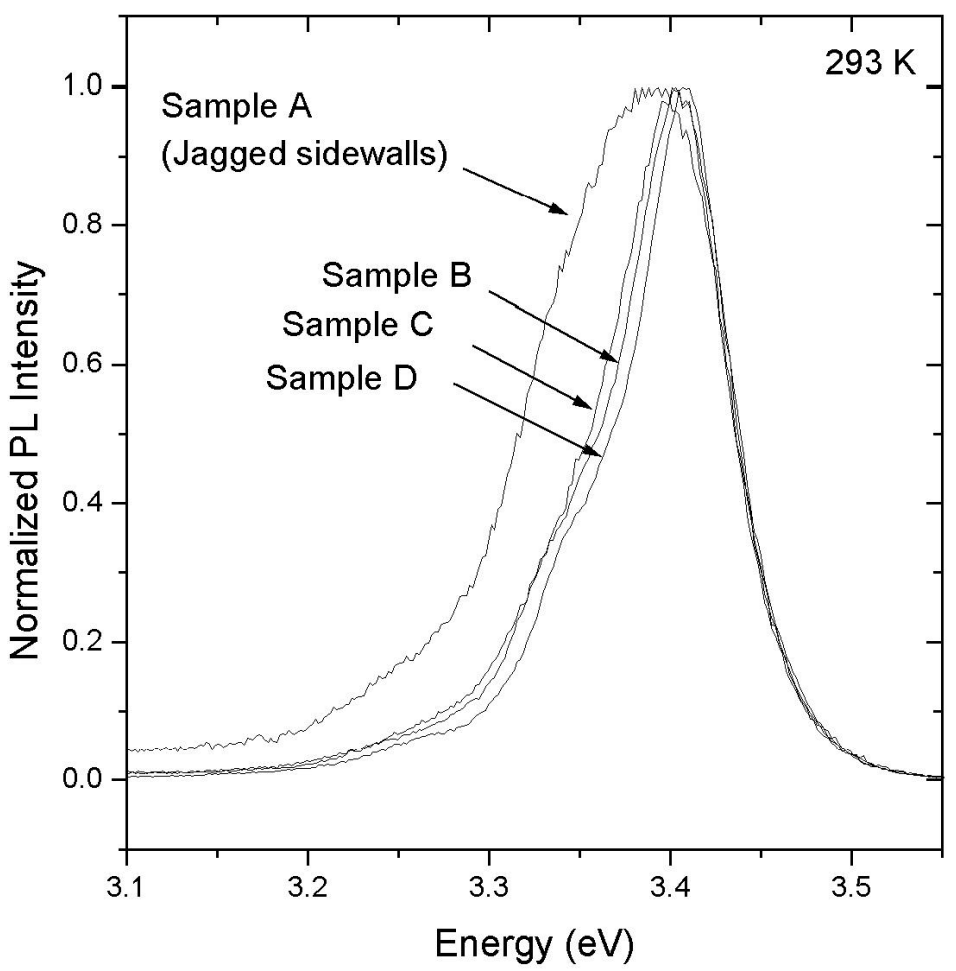

Figure 4 Room-temperature PL of samples A-D. 
related to the facet configuration of the two samples: at the onset of the overgrowth only sample A 2 has inclined facets that tend to favor the lateral spreading of dislocations (see e.g. Refs. 1 and 2).

Figure 4 shows the room-temperature PL spectra of samples A-D around the band edge of $\mathrm{GaN}$. In this experiment the light emission from both the LEO and the seed regions was collected. ${ }^{22}$ Sample A shows a fairly broad peak (FWHM $\sim 120 \mathrm{meV}$ ) centered at $3.390 \mathrm{eV}$ while samples B, C, and D have a narrower peak (FWHM $\sim 75 \mathrm{meV}$ ) centered at $\sim 3.405 \mathrm{eV}$. Although a detailed study of the optical properties is necessary to clarify the issue, the difference between the two sets of samples is most likely related to the residual strain in the LEO stripes, that is, samples B, C, and D are under slightly larger compressive stress than sample A. ${ }^{8,9,10}$ The possibility that the incorporation of impurities depend on the stripe morphology cannot be excluded and could also explain some of the differences between the two sets of samples.

\section{DISCUSSION}

Figure 2 illustrates the effect of varying the TMG and $\mathrm{NH}_{3}$ flow rates over a wide range of conditions while exposing only the $\{11 \overline{2} 0\}$ facets, which brings additional insight into the mechanisms of lateral growth. Comparing samples $\mathrm{C}$ and $\mathrm{D}$ indicates that the lateral growth rate increases with increasing $\mathrm{NH}_{3}$ flow rate (or V/III ratio); on the other hand, comparing samples $\mathrm{B}$ and $\mathrm{C}$ indicates that the lateral growth rate increases when the partial pressure of both reactants is increased while keeping the input V/III ratio constant. Thus the $\mathrm{NH}_{3}$ partial pressure appears to be more important in determining the lateral growth rate. The reasons for this are unclear but could be related to the difference in diffusivity in the gas phase or residence time on the various surfaces between the nitrogen and gallium species, such that the effective variation of partial pressures at the growing surface is significantly different than that of the input flow.

Our results indicate that the two-step process is suitable for increasing the lateral growth rate, which is a potential technological advantage. However, although samples B, C, and D exhibit a smooth morphology and a relatively low density of extended defects, their microstructure appears to be slightly inferior to that of typical samples grown with a slower lateral growth rate. Preliminary x-ray diffraction measurements indicate that the crystallographic tilt $^{4,7}$ between the seed region and the LEO region scales with the ratio $r{ }^{23}$ This tilt correlates with the density of edge dislocations observed above the edge of the mask opening and, correspondingly, at the merging front of two adjacent stripes. Therefore, the residual density of dislocations in a fully-coalesced LEO film is likely to be higher for a larger lateral growth rate. It is not clear, however, that this will be a limiting factor for the fabrication of devices based on LEO GaN.

Finally, we note that it is possible to extend the two-step scheme to variations of other growth parameters, such as growth temperature, carrier gas, total pressure, and doping level. Our preliminary results indicate that, in all cases, process variations that would normally be unfavorable to the $\{11 \overline{2} 0\}$ facets had little effect on the stripe morphology over a wide range of conditions provided that the overgrowth was initiated with smooth sidewalls. However we have observed that the $\{10 \overline{1} 1\}$ and $\{11 \overline{2} 2\}$ facets can reappear at very high fill factor and very low temperature, respectively. This suggests that the stripe morphology tends towards the equilibrium shape dictated by the driving forces (as set by the growth conditions ${ }^{18}$ ), but that the use of a seed to establish the initial morphology results in a kinetically-limited morphological evolution.

\section{CONCLUSIONS}

We have demonstrated a two-step process that results in a significant increase (up to a factor of 2.6) of the lateral growth rate while preserving smooth $\{11 \overline{2} 0\}$ sidewalls during the LEO of GaN stripes aligned in the $\langle 10 \overline{1} 0\rangle$ directions. The microstructure of the LEO stripes 
grown with the two-step process is comparable to that of stripes grown using a conventional onestep process. The two-step process allows one to extend the range of growth conditions for LEO with $\{11 \overline{2} 0\}$ sidewalls to higher $\mathrm{NH}_{3}$ partial pressure and higher V/III ratios, which should allow greater flexibility in the design of device structures based on LEO GaN.

\section{ACKNOWLEDGEMENTS}

This work was supported by ONR (C. Wood) and AFOSR (G. Witt), and made use of the MRL Central Facilities supported by the NSF under award DMR-9123048. HM acknowledges financial support from the NSERC (Canada) and a Raychem Fellowship. PF ackowledges financial support from a NDSE Graduate Fellowship provided by ONR.

\section{REFERENCES}

1. T.S. Zheleva, O.-H. Nam, M.D. Bremser, and R.F. Davis, Appl. Phys. Lett. 71, 2472 (1997).

2. A. Sakai, H. Sunakawa, and A. Usui, Appl. Phys. Lett. 71, 2259 (1997).

3. H. Marchand, J.P. Ibbetson, P.T. Fini, P. Kozodoy, S. Keller, J.S. Speck, S.P. DenBaars, and U.K. Mishra, MRS Internet J. Nitride Semicond. Res. 3, 3 (1998).

4. H. Marchand, X.-H. Wu, J.P. Ibbetson, P.T. Fini, P. Kozodoy, S. Keller, J.S. Speck, S.P. DenBaars, and U.K. Mishra, Appl. Phys. Lett. 73, 747 (1998).

5. H. Marchand, N Zhang, L. Zhao, Y Golan, P T Fini, J P Ibbetson, S. Keller, S P DenBaars, J S Speck, and U K Mishra, 25 ${ }^{\text {th }}$ Int. Symp. on Compound Semicond., Nara, Japan, 12-16 Oct. 1998.

6. O.-H. Nam, M.D. Bremser, T.S. Zheleva, and R.F. Davis, Appl. Phys. Lett. 71, 2638 (1997).

7. A. Sakai, U. Sunakawa, and A. Usui, Appl. Phys. Lett. 73, 481 (1998); A. Usui, H. Sunakawa, N. Kurado, A. Kimura, A. Sakai, and A.A. Yamaguchi, $2^{\text {nd }}$ Int. Conf. on Blue Laser and Light Emitting Diodes, Chiba, Japan, Sept. 29 - Oct. 2, 1998.

8. J.A. Freitas, Jr., O.-H. Nam, R.F. Davis, G.V. Saparin, and S.K. Obyden, Appl. Phys. Lett. 72 , 2990 (1998).

9 S. Chichibu, H. Marchand, S. Keller, P. Fini, J.P. Ibbetson, M. Minsky, S. Fleischer, J.S. Speck, J. Bowers, E. Hu, U.K. Mishra, S.P. DenBaars, T. Deguchi, T. Sota, and S. Nakamura, $2^{\text {nd }}$ Int. Conf. on Blue Laser and Light Emitting Diodes, Chiba, Japan, Sept. 29 - Oct. 2, 1998.

10. X. Li, S.G. Bishop, and J.J Coleman, Appl. Phys. Lett. 73, 1179 (1998).

11. S. Nakamura, M. Senoh, S. Nagahama, N. Isawa, T. Yamada, T. Matsushita, H. Kiyoku, Y. Sugimoto, T. Kozaki, H. Umemoto, M. Sano, M. Chocho, Appl. Phys. Lett. 72, 211 (1998).

12. P. Kozodoy, J.P. Ibbetson, H. Marchand, P.T. Fini, S. Keller, S.P. DenBaars, J.S. Speck, U.K. Mishra, Appl. Phys. Lett. 73975 (1998).

13. T. Mukai, K. Takekawa, S. Nakamura, Jpn. J. Appl. Phys. 37 L839 (1998).

14. C. Sasaoka, H. Sumakawa, A. Kimura, M. Nido, A. Usui, and A. Sakai, J. Cryst. Growth 189, 61 (1998).

15. R. Vetury, H. Marchand, J.P. Ibbetson, P.T. Fini, S. Keller, J.S. Speck, S.P. Denbaars, and U.K. Mishra, $25^{\text {th }}$ Int. Symp. on Compound Semicond., Nara, Japan, Oct 12-16, 1998

16. D. Kapolnek, S. Keller, R. Vetury, R.D. Underwood, P. Kozodoy, S.P. DenBaars, and U.K. Mishra, Appl. Phys. Lett. 71 (1997) 1204.

17. Y. Kato, S. Kitamura, K. Hiramatsu, and N. Sawaki, J. Cryst. Growth 144, 133 (1994).

18. H. Marchand, J.P. Ibbetson, P.T. Fini, S. Keller, S.P. DenBaars, J.S. Speck, and U.K. Mishra, J. Cryst. Growth (in press).

19. The fill factor (FF) is defined as the ratio of the stripe opening width to the pattern period, such that an infinitely wide mask corresponds to $\mathrm{FF}=0$ and a planar $\mathrm{GaN}$ film corresponds to $\mathrm{FF}=1$.

20. J.P. Ibbetson, H. Marchand, P.T. Fini, X.H. Wu, S. Keller, S.P. DenBaars, J.S. Speck, and U.K. Mishra, $40^{\text {th }}$ Electronic Materials Conference, Charlottesville, VA, 24-26 June 1998; H. Marchand, J.P. Ibbetson, P.T. Fini, S. Chichibu, S.J. Rosner, S. Keller, S.P. DenBaars, J.S. Speck, and U.K. Mishra, 25 ${ }^{\text {th }}$ Int. Symp. on Compound Semicond., Nara, Japan, Oct 12-16, 1998.

21. B.P. Keller, S. Keller, D. Kapolnek, W.N. Jiang, Y.-F. Wu, H. Masui, X.H. Wu, B. Heying, J.S. Speck, U.K. Mishra, and S.P. DenBaars, J. Electr. Mater. 24 (1992) 1707.

22. Selective-area PL measurements on LEO GaN and InGaN are reported in Ref. 9.

23. P.T. Fini, unpublished results. 